\title{
Early clinical and angiographic outcomes after robotic-assisted coronary artery bypass surgery
}

\author{
Michael E. Halkos, MD, MSc, ${ }^{a}$ Henry A. Liberman, MD, ${ }^{b}$ Chandan Devireddy, MD, ${ }^{b}$ Patrick Walker, BA, ${ }^{a}$ \\ Aloke V. Finn, MD, ${ }^{\mathrm{b}}$ Wissam Jaber, MD, ${ }^{\mathrm{b}}$ Robert A. Guyton, MD, ${ }^{\mathrm{a}}$ and John D. Puskas, MD, MSc ${ }^{\mathrm{a}}$
}

Objective: Robotic-assisted coronary artery bypass grafting has emerged as an alternative to traditional coronary artery bypass grafting or percutaneous intervention for patients with coronary artery disease. However, the safety and efficacy of this minimally invasive procedure have not been established in large series.

\begin{abstract}
Methods: From October 2009 to September 2012, 307 consecutive robotic-assisted coronary artery bypass grafting procedures were performed at a single US institution by 2 surgeons. Isolated, off-pump, left internal thoracic artery to left anterior descending coronary artery grafting was planned via a 3- to 4-cm non-rib-spreading minithoracotomy after robotic left internal thoracic artery harvest in all patients. Hybrid coronary revascularization was planned in 159 patients $(51.8 \%)$. Of the 199 angiograms $(64.8 \%)$ performed before discharge, 63 were performed as completion angiograms in a hybrid suite immediately after left internal thoracic artery-left anterior descending artery grafting.

Results: Thirty-day mortality occurred in 4 patients $(1.3 \%)$, conversion to sternotomy occurred in 16 patients $(5.2 \%)$, postoperative myocardial infarction occurred in 5 patients $(1.6 \%)$, and reexploration for bleeding occurred in 7 patients $(2.3 \%)$. There was $1(0.3 \%)$ postoperative stroke. For the 199 patients with follow-up angiography before discharge, the left internal thoracic artery was confirmed to be patent ( $<50 \%$ stenosis) in 189 patients $(95.0 \%)$. Among the 10 patients with significant ( $\geq 50 \%$ stenosis) defects, 5 had graft occlusion or distal left anterior descending occlusion, 2 had poor flow distal to the anastomosis, and 3 had anastomotic lesions ( $\geq 50 \%$ stenosis). Among the 63 patients with intraoperative completion angiography, 5 patients underwent surgical graft revision, 3 patients underwent minithoracotomy, and 2 patients underwent conversion to sternotomy.
\end{abstract}

Conclusions: Robotic-assisted coronary artery bypass grafting is an effective alternative to traditional coronary artery bypass grafting for patients with single or multivessel coronary artery disease, with comparable short-term clinical and angiographic results. (J Thorac Cardiovasc Surg 2014;147:179-85)

Coronary artery bypass grafting $(\mathrm{CABG})$ is an established method of treating patients with coronary artery disease, with recent trials reemphasizing its efficacy and durability. ${ }^{1,2}$ An important component of the benefit conferred by CABG is derived from the left internal thoracic artery (LITA) graft to the left anterior descending (LAD) coronary artery. Minimally invasive approaches to CABG have become more commonplace, fueled in part by patients' desire for less-invasive procedures, as well as

From The Clinical Research Unit, ${ }^{\text {a }}$ Division of Cardiothoracic Surgery, and the Division of Cardiology, ${ }^{b}$ Emory University School of Medicine, Atlanta, Ga.

Disclosures: Dr Halkos serves as a consultant for Intuitive Surgical, Inc, for case observations. All other authors have nothing to disclose with regard to commercial support.

Read at the 39th Annual Meeting of The Western Thoracic Surgical Association, Coeur d'Alene, Idaho, June 26-29, 2013.

Received for publication June 18, 2013; revisions received Aug 24, 2013; accepted for publication Sept 4, 2013; available ahead of print Oct 29, 2013

Address for reprints: Michael E. Halkos, MD, MSc, Division of Cardiothoracic Surgery, Emory University School of Medicine, 550 Peachtree St, NE, 6th Floor MOT, Atlanta, GA 30308 (E-mail: mhalkos@emory.edu).

$0022-5223 / \$ 36.00$

Copyright (c) 2014 by The American Association for Thoracic Surgery

http://dx.doi.org/10.1016/j.jtcvs.2013.09.010 significant technologic advances in robotics, perfusion devices, off-pump CABG, and retraction systems.

The 3 most common minimally invasive $\mathrm{CABG}$ procedures use a sternal-sparing approach and include minimally invasive direct coronary artery bypass (MIDCAB), robotic-assisted coronary artery bypass $(\mathrm{CAB})$, and robotic-assisted totally endoscopic coronary artery bypass (TECAB). Each approach has unique advantages and disadvantages, but results have been excellent when performed by experienced surgeons.

Robotic-assisted CAB capitalizes on the main advantage of surgical revascularization, the LITA-LAD graft; although diagonal grafting is also possible, circumflex and right coronary vessels are usually treated with percutaneous coronary intervention (PCI) when robotic-assisted LITA-LAD grafting is performed in patients with multivessel disease. The LITA harvest, pericardiotomy, and LAD identification are accomplished with robotic assistance, but the anastomosis is performed manually, under direct vision, through a non-rib-spreading 3- to $4-\mathrm{cm}$ anterolateral thoracotomy without the use of cardiopulmonary bypass. The purpose of this analysis is 


$$
\begin{aligned}
& \text { Abbreviations and Acronyms } \\
& \begin{aligned}
\text { CAB } & =\text { coronary artery bypass } \\
\text { CABG } & =\text { coronary artery bypass grafting } \\
\text { LAD } & =\text { left anterior descending } \\
\text { LITA } & =\text { left internal thoracic artery } \\
\text { MIDCAB }= & \text { minimally invasive direct coronary } \\
& \text { artery bypass } \\
\text { OR } & =\text { operating room } \\
\text { PCI } & =\text { percutaneous coronary intervention } \\
\text { PROM } & =\text { predicted risk of mortality } \\
\text { TECAB } & =\text { totally endoscopic coronary artery } \\
& \text { bypass }
\end{aligned}
\end{aligned}
$$

to describe the short-term clinical and angiographic results in a large consecutive cohort of patients undergoing robotic-assisted $\mathrm{CAB}$ for both isolated $\mathrm{LAD}$ and multivessel disease.

\section{MATERIALS AND METHODS \\ Patients and Design}

During the 37-month period between October 2009 and September 2012, data from 307 consecutive patients undergoing robotic-assisted $\mathrm{CAB}$ were prospectively entered into a customized database that included operative, technical, and angiographic details that were not available from the Society of Thoracic Surgeons (STS) database. This database was then merged with data from the STS database and retrospectively reviewed. All consecutive cases from 2 surgeons, including the earliest learning curve cases, were included in the analysis. The institutional review board at Emory University in compliance with Health Insurance Portability and Accountability Act regulations and the Declaration of Helsinki approved the study. The institutional review board waived the need for individual patient consent.

\section{Indications and Contraindications}

Patients eligible for robotic-assisted $\mathrm{CAB}$ had clinical and anatomic indications for surgical coronary revascularization. These patients (1) presented with isolated LAD that was not amenable to PCI or had LAD disease that was considered better treated with LITA-LAD grafting or (2) presented with multivessel coronary disease that was amenable to a hybrid revascularization approach, defined as LITA-LAD grafting combined with PCI of non-LAD lesions.

Absolute contraindications to robotic-assisted $\mathrm{CAB}$ included hemodynamically unstable patients, those with intra-aortic balloon pumps, or those with evolving myocardial infarction. Patients with a poor or nongraftable distal target vessel, previous sternotomy or thoracotomy, body mass index greater than 40 , or severe lung disease with inability to tolerate single-lung ventilation were considered relative contraindications.

\section{Technical Details}

All patients underwent single lung ventilation using a dual lumen endotracheal tube or bronchial blocker or bilateral lung low tidal volume ventilation. Beta-blockers were administered within 24 hours of the procedure. Aspirin $1000 \mathrm{mg}$ was administered per rectum after induction. Before dividing the LITA, $180 \mathrm{IU} / \mathrm{kg}$ of intravenous heparin is administered to achieve an activated clotting time greater than 350 seconds. The patient is positioned with a roll under the left chest beneath the scapula to allow the left shoulder to be lowered when the left upper extremity is tucked loosely. A 12-mm thoracoscopic trocar is inserted into the fourth or fifth interspace, in the midportion of the sternum, approximately 2 fingerbreadths lateral to the midclavicular line. Ideally, the camera port is inserted at the location that is at a 45-degree angle to the plane of the sternum. This allows optimal visualization of the LITA but adequate distance away from it to allow for easy dissection. Before inserting the trocar, the ventilator is disconnected allowing the heart to fall toward the right hemithorax. The chest is initially entered with a blunt instrument to prevent ventricular or pulmonary injury with port placement. After the trocar is inserted, the chest is insufflated with carbon dioxide at 10 to $15 \mathrm{~mm} \mathrm{Hg}$, and the right lung is ventilated. An 8.5-mm trocar is placed 2 interspaces above the camera port under direct vision slightly medial to the camera port. The final $8.5-\mathrm{mm}$ trocar is placed 2 interspaces below the camera port in line or slightly medial to the camera port. The da Vinci Robotic surgical system (Intuitive Surgical, Sunnyvale, Calif) is then docked and instruments inserted under direct vision. The surgeon then scrubs out, and the LITA is harvested using both the robotic monopolar cautery spatula and the bipolar cautery forceps. In general, the LITA is harvested in a semiskeletonized fashion. Overlying muscle and fascia are removed only to provide complete exposure during the harvest. After LITA harvest, pericardial fat is dissected off the pericardium and draped laterally. A small pericardiotomy posterior to the left phrenic nerve can be performed to facilitate pericardial drainage. A full longitudinal pericardiotomy is then performed anteriorly, and the LAD is identified and inspected for a suitable grafting site. The LITA is divided distally between clips after systemic heparinization and clipped to the edge of the pericardium or allowed to fall toward the apex.

At this point, the robotic system is undocked, and the surgeon uses the endoscope to identify the planned site of anastomosis without carbon dioxide insufflation. This allows the heart to return to its natural position within the chest. A spinal needle is inserted through the chest wall to identify the precise location for the incision over the target LAD site. In female patients, the breast is usually retracted medially for the robotic portion of the procedure and then repositioned superiorly/laterally to facilitate an infrathoracic incision if feasible. All ports are then removed, and the anterolateral thoracotomy incision is made. A soft tissue retractor (CardioVations, Edwards Lifesciences, Irvine, Calif) is used to provide exposure through the interspace. Rib spreading is avoided. The LITA is retrieved into the operating field and prepared. The LAD target is exposed and stabilized using a minimally invasive stabilizer (Octopus NUVO, Medtronic, Inc, Minneapolis, Minn), and the anastomosis is performed manually off-pump using fine 8-0 monofilament suture.

\section{Angiography}

Since September 2010, it has been our preference to use a hybrid operating room (OR) when available to perform completion angiograms or 1-stop hybrid revascularization when indicated. During our initial experience, we routinely performed selective LITA angiography in the postoperative period to assess graft patency. Patency was defined as less than $50 \%$ stenosis in the graft or at the anastomosis. For cases in which a completion angiogram in the hybrid suite revealed graft defects or target vessel errors, the anastomosis was revised during the same operative setting, regardless of whether there was clinical evidence of ischemia.

\section{RESULTS}

From October 2009 to September 2012, 307 patients underwent planned robotic-assisted CAB with LITA-LAD grafting. In all patients, the intention was LITA-LAD grafting as an isolated procedure $(148,48.2 \%)$ or as part of a hybrid coronary revascularization strategy for multivessel coronary disease $(159,51.8 \%)$. All consecutive cases for 2 surgeons during this interval were included 
(surgeon 1, 235 cases; surgeon 2, 72 cases), which includes learning curve cases and represents the early experience of our robotic-assisted $\mathrm{CAB}$ program. Of the 228 cases performed after September 2010, 188 of these were performed in the hybrid OR. Concomitant or "1-stage" hybrid revascularization procedures were performed in 21 patients, and intraoperative completion angiograms were performed in 63 patients.

\section{Demographic and Patient Variables}

The mean age was $62.7 \pm 11.6$ years, $71.3 \%$ of patients were female, and the mean ejection fraction was $55.5 \% \pm 8.7 \%$. The mean STS predicted risk of mortality (PROM) score was $1.2 \% \pm 1.7 \%$, and the predicted risk of permanent stroke was $0.97 \% \pm 1.0 \%$. There were 50 patients $(16.3 \%)$ with STS PROM scores more than $2.0 \%, 13$ of whom had STS PROM scores more than $5 \%$. Other demographic variables are listed in Table 1.

\section{Clinical Outcomes}

Thirty-day mortality occurred in 4 patients $(1.3 \%)$, conversion to sternotomy occurred in 16 patients $(5.2 \%)$, postoperative myocardial infarction occurred in 5 patients $(1.6 \%)$, and reexploration for bleeding occurred in 7 patients $(2.3 \%)$. Reasons for conversion to sternotomy are described in Table 2. None of the postoperative deaths were due to graft failure. There was only $1(0.3 \%)$ postoperative stroke, which was nonembolic and related to a brief period of postoperative hypotension in a patient who had a history of previous stroke. The incidence of blood transfusion was low, with only 66 patients $(21.5 \%)$ receiving any blood transfusion. Postoperative repeat revascularization occurred in 8 of 307 patients $(2.6 \%)$.

TABLE 1. Demographic and clinical baseline characteristics

\begin{tabular}{lc}
\hline \multicolumn{1}{c}{ Variable } & $\mathbf{N}=\mathbf{3 0 7}$ \\
\hline Age (y) & $62.7 \pm 11.6$ \\
Male/female ratio & $219 / 88$ \\
Body mass index & $28 \pm 4.7$ \\
Smoker & $79(25.7 \%)$ \\
Diabetes & $109(35.5 \%)$ \\
Dyslipidemia & $296(96.4 \%)$ \\
Hypertension & $282(91.9 \%)$ \\
Peripheral vascular disease & $38(12.4 \%)$ \\
Previous stroke & $12(3.9 \%)$ \\
Renal failure-hemodialysis & $10(3.3 \%)$ \\
NYHA class III-IV & $10(3.3 \%)$ \\
Prior myocardial infarction & $161(52.4 \%)$ \\
Ejection fraction & $55.5 \% \pm 8.7 \%$ \\
Left main disease & $37(12.1 \%)$ \\
STS PROM & $1.2 \% \pm 1.7 \%$ \\
STS PROPS & $0.97 \% \pm 1.0 \%$ \\
\hline NYHA, New York Heart Association; $P R O M$, predicted & risk of mortality; \\
PROPS, predicted risk of postoperative stroke; STS, Society of Thoracic Surgeons.
\end{tabular}

TABLE 2. Conversion to sternotomy

\begin{tabular}{lc}
\hline \multicolumn{1}{c}{ Reasons for conversion to sternotomy } & $\mathbf{N}=\mathbf{1 6}$ \\
\hline Technical difficulty with LITA-LAD anastomosis & 6 \\
LITA injury/dissection/inadequate length & 3 \\
Wrong vessel grafted & 2 \\
Ventricular arrhythmia & 1 \\
Equipment malfunction & 1 \\
Right ventricular epicardial injury from port placement & 1 \\
Bleeding during LITA harvest & 1 \\
Left chest adhesions & 1 \\
\hline LAD, Left anterior descending coronary artery; LITA, left internal thoracic artery.
\end{tabular}

Reintubation occurred in 4 of 123 patients who were extubated in the OR. Additional outcomes can be seen in Table 3. Outcomes among patients with STS PROM scores of $2.0 \%$ or greater are shown in Table 4.

\section{Angiographic Outcomes}

Graft defects, determined by intraoperative and postoperative angiography, were identified in 14 of 199 patients $(7.0 \%)$ (Figure 1). This included 10 patients with nonpatent grafts (stenosis $\geq 50 \%$ ) and 4 patients with target vessel errors. Overall, 189 of 199 grafts $(95.0 \%)$ were patent ( $<50 \%$ stenosis). According to Fitzgibbon criteria to define patency, Fitzgibbon A + B patency was 96.5\% (192/199 patients). In the 10 patients with graft failure, 5 had occluded grafts, 2 had poor flow distal to the anastomosis, and 3 had anastomotic stenosis. However, 3 of these grafts were revised during the same operative setting after the completion angiogram. Graft failure was noted in the other 7 patients on postoperative angiograms done before hospital discharge; 6 patients were treated percutaneously, and 1 patient underwent redo-multivessel CABG. Only 3 of these

TABLE 3. Clinical outcomes of entire cohort

\begin{tabular}{lc}
\hline \multicolumn{1}{c}{ Outcome } & $\mathbf{N}=\mathbf{3 0 7}$ \\
\hline 30-d mortality & $4(1.3 \%)$ \\
Stroke & $1(0.3 \%)$ \\
Myocardial infarction & $5(1.6 \%)$ \\
Conversion to sternotomy & $16(5.2 \%)$ \\
Reexploration for bleeding & $7(2.3 \%)$ \\
Repeat revascularization & $8(2.6 \%)$ \\
Postoperative atrial fibrillation & $47(15.3 \%)$ \\
Renal failure & $6(2.0 \%)$ \\
No. of patients receiving any blood product & $66(21.5 \%)$ \\
$\quad$ transfusion & \\
Superficial wound infection & $6(2.0 \%)$ \\
Sternal complications/mediastinitis & 0 \\
Extubated in OR & $123(40.0 \%)$ \\
Prolonged ventilation (>24 h) & $18(5.9 \%)$ \\
Median ventilation time & $2.0 \mathrm{~h}($ range, $0-193)$ \\
Median ICU length of stay & $1.0 \mathrm{~d}($ range, $0-19)$ \\
Median hospital length of stay & $4.0 \mathrm{~d}($ range, $2-27)$ \\
\hline
\end{tabular}

$I C U$, Intensive care unit; $O R$, operating room. 
TABLE 4. Clinical outcomes of high-risk patients (Society of Thoracic Surgeons predicted risk of mortality $\geq \mathbf{2 . 0} \%$ )

\begin{tabular}{lc}
\hline \multicolumn{1}{c}{ Outcome } & $\mathbf{N}=\mathbf{5 0}$ \\
\hline Mean STS PROM score & $4.3 \% \pm 2.5 \%$ \\
$30-\mathrm{d}$ mortality & $1(2.0 \%)$ \\
Stroke & $1(2.0 \%)$ \\
Myocardial infarction & $1(2.0 \%)$ \\
Conversion to sternotomy & $3(6.0 \%)$ \\
Reexploration for bleeding & $1(2.0 \%)$ \\
Repeat revascularization & 0 \\
Postoperative atrial fibrillation & $13(26.0 \%)$ \\
Renal failure & $3(6.0 \%)$ \\
No. of patients receiving any blood product & $20(40.0 \%)$ \\
$\quad$ transfusion & 0 \\
Superficial wound infection & 0 \\
Sternal complications/mediastinitis & $14(28.0 \%)$ \\
Extubated in OR & $6(12.0 \%)$ \\
Prolonged ventilation (>24 h) & $6.3 \mathrm{~h}($ range, $0-114)$ \\
Median ventilation time & $2.0 \mathrm{~d}($ range, $0-17)$ \\
Median ICU length of stay & $6.0 \mathrm{~d}($ range, $2-27)$ \\
Median hospital length of stay & \\
\hline$I C U$, Intensive care unit; $O R$, operating room; STS, Society of Thoracic Surgeons; \\
$P R O M$, predicted risk of mortality.
\end{tabular}

10 patients had clinical evidence of ischemia. Therefore, of the 8 patients who underwent repeat revascularization, 6 underwent PCI for graft failure, 1 underwent PCI for target vessel error (inadvertent LITA-diagonal grafting), and 1 underwent redo-multivessel CABG for graft failure.

The diagonal rather than the LAD coronary artery was inadvertently grafted in 4 patients. In 2 of these patients, the patent LITA-diagonal grafts were discovered on the intraoperative completion angiogram, which allowed for revision in the hybrid OR under the same anesthesia setting. The other 2 patients were found to have patent diagonal grafts on staged postoperative angiography; 1 had a stent placed in the proximal LAD because of an intervening lesion between the diagonal and LAD arteries.

Therefore, procedural success, defined as patients leaving the OR with patent grafts ( $<50 \%$ stenosis) to planned target vessels, was $95.5 \%$ (190/199). This takes into account the 5 grafts that were revised in the OR and the 2 inadvertent diagonal grafts that were discovered on postoperative angiogram. Alternatively, if Fitzgibbon criteria were used to define graft patency (Fitzgibbon A + B), the procedural success was $97.0 \%(193 / 199)$.

\section{Learning Curve}

In this study, procedural times for each surgeon steadily declined (Figure 2). For surgeon 1 (MH, 235 cases), the mean procedure time (incision to close) for the last 10 cases was 178 minutes. For surgeon 2, (JP, 72 cases), the mean procedure time for the last 10 cases was 219 minutes, but the learning curves are well matched according to case volume. For patients undergoing 1-stop or concomitant hybrid coronary revascularization, the mean time for both surgery and PCI was 281 minutes. For the first 153 cases, there were 9 graft defects $(5.9 \%)$; for the last 154 cases, there were 5 graft defects $(3.2 \%)$. Conversions occurred in $9(5.9 \%)$ of the first 153 cases and $7(4.5 \%)$ of the last 154 cases.

\section{DISCUSSION}

Minimally invasive $\mathrm{CAB}$ procedures have become an accepted method of surgical revascularization. By capitalizing on the proven durability and survival advantage associated with LITA-LAD grafting, these less-invasive surgical options can be applied to patients with isolated LAD or multivessel coronary disease. Furthermore,

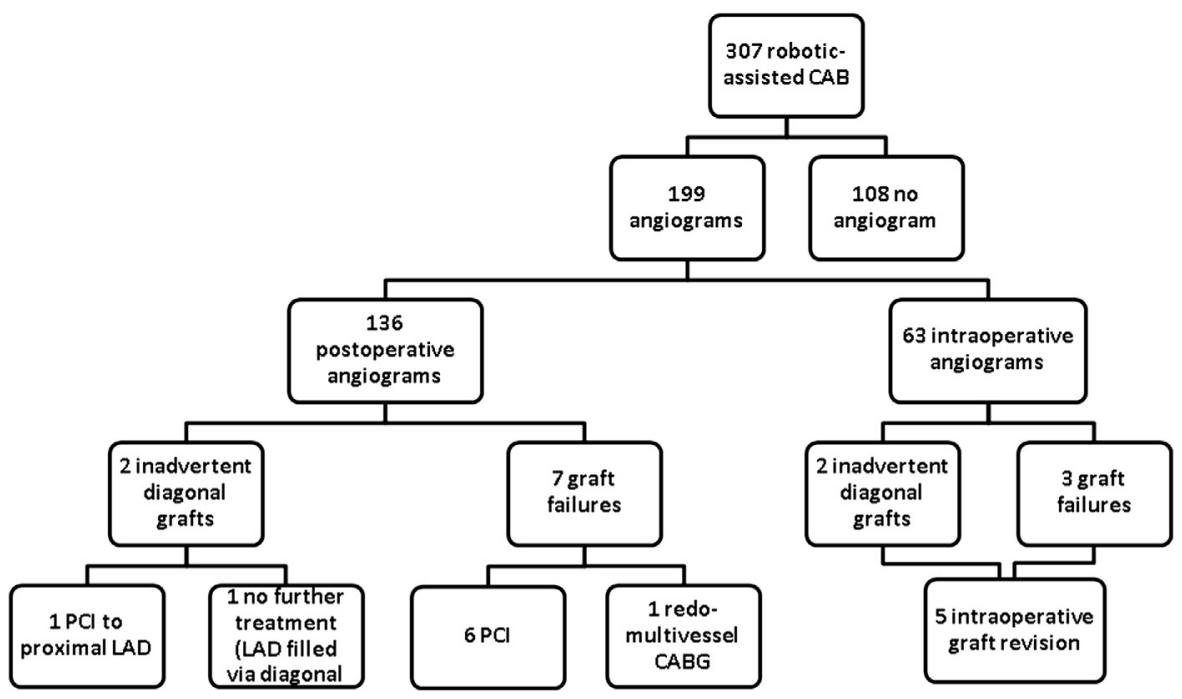

FIGURE 1. Flow diagram of patients undergoing robotic-assisted CABG categorized by angiography and graft defects. $C A B$, Coronary artery bypass; $C A B G$, coronary artery bypass grafting; $L A D$, left anterior descending; $P C I$, percutaneous coronary intervention. 


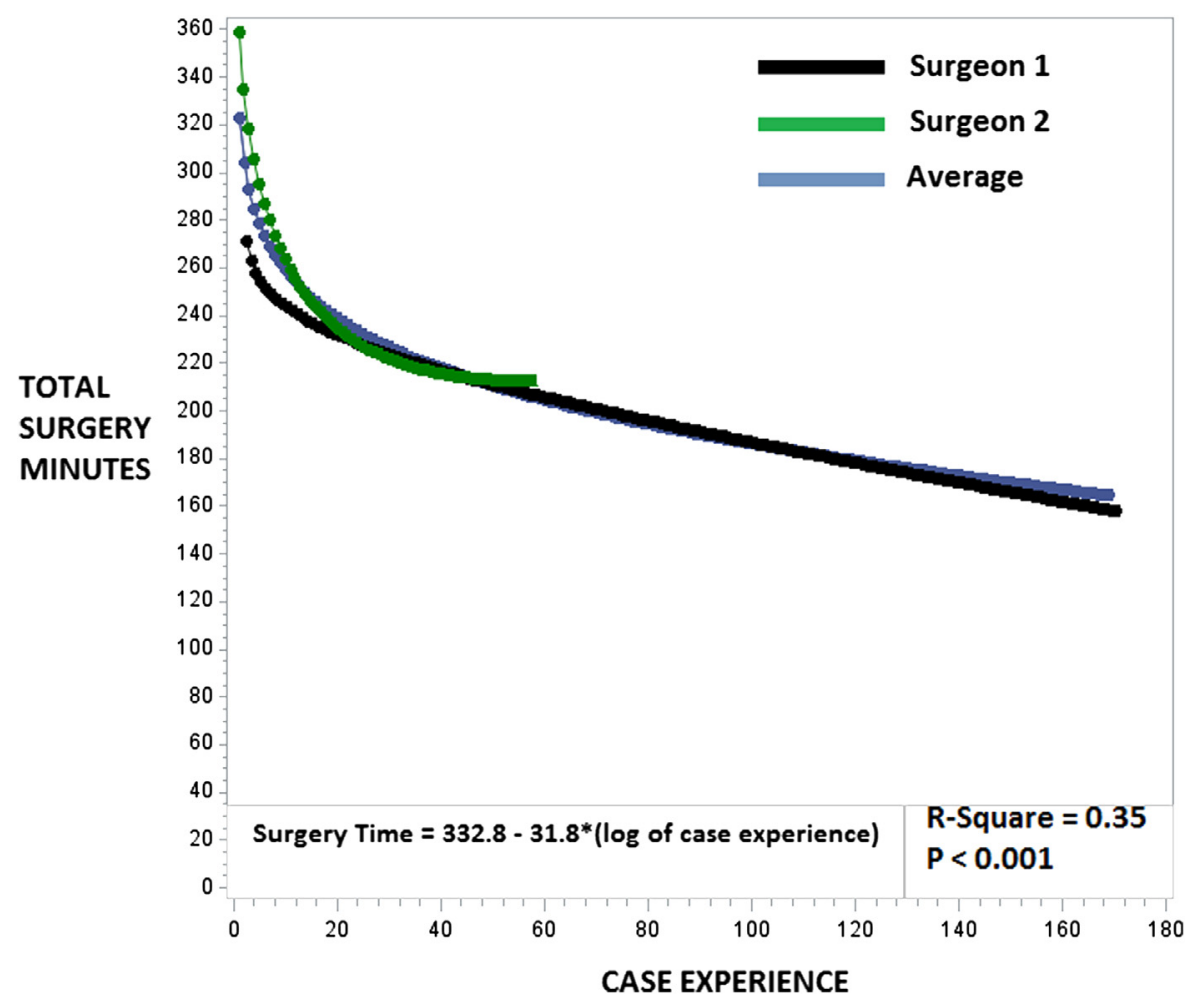

FIGURE 2. Plot of surgery time versus log of case experience revealed statistically significant effect of experience on duration of operation.

cardiologists may be more willing to refer patients for this approach providing patients with the best available treatment option for the LAD, the LITA. Although a nonrobotic approach represents a viable alternative to sternotomy, robotic techniques provide high-definition intrathoracic exposure and 3-dimensional telemanipulation for LITA harvest, pericardiotomy, and totally endoscopic multivessel grafting. Nonetheless, for less-invasive surgical revascularization options to become widely adopted, both clinical and angiographic outcomes need to be comparable to more conventional sternotomy approaches.

In this study, isolated off-pump LITA-LAD grafting was performed via a sternal-sparing, non-rib-spreading 3- to 4-cm anterolateral thoracotomy after robotic LITA harvest and pericardiotomy. In contrast to TECAB, all anastomoses were performed manually with direct vision, in a manner similar to that performed via sternotomy. The main disadvantages of this approach are limited exposure of the entire LAD and the inability to graft other major coronary territories. The main advantage is that the operation is less technically challenging than TECAB, avoiding the need for advanced skills required for robotic anastomosis and perfusion techniques, and avoiding larger incisions and chest wall retraction associated with MID$\mathrm{CAB}$. For patients suitable for a hybrid revascularization strategy, percutaneous intervention with stenting of non-LAD lesions can be combined with robotic-assisted
LITA-LAD grafting. The benefits of a hybrid approach for multivessel disease will need to be validated in clinical trials.

The clinical results of this series are comparable to those of other published results. For MIDCAB, Holzhey and colleagues $^{3}$ demonstrated a postoperative LITA-LAD patency rate of $95.5 \%$, perioperative stroke and mortality rate of less than $1 \%$, and a conversion rate of $1.8 \%$. McGinn and colleagues ${ }^{4}$ reported excellent short-term results with multivessel grafting via a MIDCAB incision with a perioperative mortality rate of $1.3 \%$, conversion rate of $3.8 \%$, and reoperation rate for bleeding of $2.2 \%$. For TECAB procedures, Bonatti and colleagues ${ }^{5}$ reported results in more than 400 TECAB cases with a $0.7 \%$ mortality, $14 \%$ conversion rate, and $1.7 \%$ stroke rate. Other centers also have reported excellent short-term outcomes. $^{6-12}$ Postoperative stroke, one of the main limitations of CABG compared with $\mathrm{PCI},{ }^{1,2}$ occurred in only 1 patient in this series and was nonembolic in cause. Compared with TECAB and multivessel MIDCAB approaches, the revascularization strategy described in our series avoids any manipulation of the ascending aorta and avoids antegrade or retrograde perfusion with cardiopulmonary bypass, which may minimize the risk of atheroembolic stroke. Furthermore, this approach avoids the larger incision, chest wall retraction, and possible rib fracture associated with MIDCAB techniques, which 
theoretically would imply less postoperative pain. With this less-invasive approach, atrial fibrillation occurred in only $15 \%$ of patients, which may affect longer-term stroke rates. Likewise, other resource use measures were favorable for this study.

It is important to compare the clinical outcomes of less-invasive approaches with traditional $\mathrm{CABG}^{13-15}$; however, the most discriminatory outcome measure that warrants comparison is graft quality and patency. Despite the availability of computed tomography angiography and intraoperative transit time flow measurements, the most reliable method of documenting the quality of the anastomosis is conventional angiography. In this series, 199 patients underwent intraoperative or postoperative angiography. In our experience, LITA angiograms were routinely performed in our first 150 cases and are always performed as part of hybrid revascularization procedures when the surgical session is performed first or concomitantly with PCI of non-LAD vessels.

With a hybrid OR, completion angiograms can be performed under anesthesia, which allows for surgical revision when graft defects are identified. Zhao and colleagues ${ }^{16}$ reported that $12 \%$ of bypass grafts had defects or target vessel errors identified on completion angiography before sternotomy closure, with $9.4 \%$ undergoing surgical revision or open PCI. Findings detected on completion angiograms in the current study led to graft revision in 5 of 63 cases $(7.9 \%)$, which may have prevented adverse clinical outcomes and graft failure. It is possible that our overall angiographic outcomes would have been better if all cases could have been performed in a hybrid OR, which was not available until the second year of our program. From a practical standpoint, this may not always be possible, because hybrid rooms are used by other services and for other procedures, and require considerable financial resources to develop and maintain. Nonetheless, the ability to perform completion angiograms for procedures without an established track record has been an important part of our learning curve and quality control, and has been vital for programmatic growth. Our current policy is to perform completion angiography in cases in which there are any concerns about the quality of the graft, anastomosis, or target vessel, and in all technically challenging cases. This includes chronically occluded LAD arteries and small, calcified, or diffusely diseased target vessels, regardless of transit time flow measurements or clinical status.

There is undoubtedly a learning curve that exists for any minimally invasive CABG procedure ${ }^{17}$ Holzhey and colleagues ${ }^{18}$ were able to demonstrate that outcomes after MIDCAB were surgeon and case-load dependent, requiring up to 50 to 100 cases to achieve proficiency. Wiedemann and associates ${ }^{19}$ confirmed that more complex TECAB procedures result in longer operative times, which may adversely influence postoperative outcomes. Our results mirror those of other studies. With this approach, there are 2 portions of the procedure associated with a learning curve: (1) the robotic LITA harvest and pericaridotomy; and (2) off-pump LITA-LAD grafting via a small anterolateral thoracotomy. Both surgeons in this study had extensive off-pump experience via sternotomy before adopting this approach, which undoubtedly improved the proficiency of off-pump LITA-LAD grafting via a small thoracotomy. Both of the surgeons in this study had limited MIDCAB experience. We observed a gradual reduction in the length of operation with increasing surgical experience and fewer errors with increasing experience. Our results suggest that at least 50 to 100 cases are required to achieve proficiency, which depends not only on the individual surgeon but also on the entire cardiovascular team. Although target vessel errors can occur during $1 \%$ to $2 \%$ of sternotomy cases, ${ }^{16}$ this error is easier to make with a robotic-assisted approach. With TECAB, all coronary territories can be visualized, but during robotic-assisted or MIDCAB approaches, exposure is dependent on the size of the skin incision through which the anastomosis is performed. It is our policy to convert to sternotomy whenever there is a concern about patient safety, hemodynamic stability, or quality of the anastomosis, and we do not consider conversion a failure.

\section{CONCLUSIONS}

Although this series is limited by its retrospective nature and relatively small sample size, these results add to the growing body of literature that minimally invasive CABG procedures can be performed with excellent short-term clinical and angiographic outcomes. Acknowledging that a long learning curve exists and implementing quality control measures such as routine intraoperative or postoperative angiography are important components that may optimize both clinical outcomes and graft success. Close collaboration with the surgical team and other providers by using a multidisciplinary approach is essential to ensure excellent outcomes with these less-invasive procedures.

\section{References}

1. Serruys PW, Morice MC, Kappetein AP, Columbo A, Holmes OR, Mack MJ, et al. Percutaneous coronary intervention versus coronary-artery bypass grafting for severe coronary artery disease. N Engl J Med. 2009;360:961-72.

2. Farkouh ME, Domanski M, Sleeper LA, Siami FS, Dangas G, Mack M, et al. Strategies for multivessel revascularization in patients with diabetes. $N$ Engl J Med. 2012;367:2375-84.

3. Holzhey DM, Cornely JP, Rastan AJ, Davierwala P, Mohr FW. Review of a 13-year single-center experience with minimally invasive direct coronary artery bypass as the primary surgical treatment of coronary artery disease. Heart Surg Forum. 2012;15:E61-8.

4. McGinn JT Jr, Usman S, Lapierre H, Pothula VR, Mesana TG, Ruel M. Minimally invasive coronary artery bypass grafting: dual-center experience in 450 consecutive patients. Circulation. 2009;120(11 Suppl):S78-84.

5. Bonatti J, Schachner T, Bonaros N, Lehr EJ, Zimrin D, Griffith B. Robotically assisted totally endoscopic coronary bypass surgery. Circulation. 2011;124: 236-44. 
6. Vassiliades TA Jr, Reddy VS, Puskas JD, Guyton RA. Long-term results of the endoscopic atraumatic coronary artery bypass. Ann Thorac Surg. 2007;83: 979-85.

7. Thiele H, Neumann-Schniedewind P, Jacobs S, Boudriot E, Walther T, Mohr FW, et al. Randomized comparison of minimally invasive direct coronary artery bypass surgery versus sirolimus-eluting stenting in isolated proximal left anterior descending coronary artery stenosis. J Am Coll Cardiol. 2009;53:2324-31.

8. Kiaii B, McClure RS, Stewart P, Rayman R, Swinamer SA, Suematsu Y, et al. Simultaneous integrated coronary artery revascularization with long-term angiographic follow-up. J Thorac Cardiovasc Surg. 2008;136:702-8.

9. Vassiliades TA Jr, Douglas JS, Morris DC, Block PC, Ghazzal Z, Rab ST, Cates CU. Integrated coronary revascularization with drug-eluting stents: immediate and seven-month outcome. J Thorac Cardiovasc Surg. 2006;131:956-62.

10. de Canniere D, Wimmer-Greinecker G, Cichon R, Gulielmos V, Van Praet F, Seshadri-Kreaden U, Falk V. Feasibility, safety, and efficacy of totally endoscopic coronary artery bypass grafting: multicenter European experience. J Thorac Cardiovasc Surg. 2007;134:710-6.

11. Kon ZN, Brown EN, Tran R, Joshi A, Reicher B, Grant MC, et al. Simultaneous hybrid coronary revascularization reduces postoperative morbidity compared with results from conventional off-pump coronary artery bypass. J Thorac Cardiovasc Surg. 2008;135:367-75.

12. Bonaros N, Schachner T, Wiedemann D, Oehlinger A, Ruetzler E, Feuchtner G, et al. Quality of life improvement after robotically assisted coronary artery bypass grafting. Cardiology. 2009;114:59-66.
13. Bainbridge D, Cheng D, Martin J, Novick R. Does off-pump or minimally invasive coronary artery bypass reduce mortality, morbidity, and resource utilization when compared with percutaneous coronary intervention? A meta-analysis of randomized trials. J Thorac Cardiovasc Surg. 2007;133:623-31.

14. Halkos ME, Vassiliades TA, Myung RJ, Kilgo P, Thourani VH, Cooper WA, et al. Sternotomy versus nonsternotomy LIMA-LAD grafting for single-vessel disease. Ann Thorac Surg. 2012;94:1469-77.

15. Lamy A, Devereaux PJ, Prabhakaran D, Taggart DP, Hu S, Paolasso E, et al. Effects of off-pump and on-pump coronary-artery bypass grafting at 1 year. N Engl J Med. 2013;368:1179-88

16. Zhao DX, Leacche M, Balaguer JM, Boudoulas KD, Damp JA, Greelish JP, et al Routine intraoperative completion angiography after coronary artery bypass grafting and 1-stop hybrid revascularization results from a fully integrated hybrid catheterization laboratory/operating room. J Am Coll Cardiol. 2009;53:232-41.

17. Kappert U, Tugtekin SM, Cichon R, Braun M, Matschke K. Robotic totally endoscopic coronary artery bypass: a word of caution implicated by a five-year follow-up. J Thorac Cardiovasc Surg. 2008;135:857-62.

18. Holzhey DM, Jacobs S, Walther T, Mochalski M, Mohr FW, Falk V. Cumulative sum failure analysis for eight surgeons performing minimally invasive direct coronary artery bypass. J Thorac Cardiovasc Surg. 2007;134:663-9.

19. Wiedemann D, Bonaros N, Schachner T, Weidinger F, Lehr EJ, Vesely M, Bonatti J. Surgical problems and complex procedures: Issues for operative time in robotic totally endoscopic coronary artery bypass grafting. $J$ Thorac Cardiovasc Surg. 2012;143:639-47. 